\title{
Electromagnetic brain activity evoked by affective stimuli in schizophrenia
}

\author{
BRIGITTE ROCKSTROH, ${ }^{\text {a }}$ MARKUS JUNGHÖFER, ${ }^{a}$ THOMAS ELBERT, ${ }^{\mathrm{a}}$ GIULIA BUODO, \\ AND GREGORY A. MILLER ${ }^{\mathrm{c}}$ \\ ${ }^{a}$ Department of Psychology, University of Konstanz, Konstanz, Germany \\ ${ }^{b}$ Department of Psychology, University of Padova, Padova, Italy \\ ${ }^{c}$ Departments of Psychology and Psychiatry and Beckman Institute Brain Imaging Center, University of Illinois at Urbana-Champaign, Urbana, \\ Illinois, USA
}

\begin{abstract}
Schizophrenia is typically associated with cognitive deficits, but symptoms also point to alterations in the processing of affective material, with potential impact on behavioral performance. This impact may unfold on multiple time scales, but initial processing of rapidly unfolding social cues may be particularly important. MEG-assessed regional brain activity associated with the capacity to process the emotional content of rapid visual stimuli (3/s) was examined in 12 individuals with schizophrenia and 12 matched controls. Patients showed less differentiation of emotional versus neutral stimuli 90-300 ms following picture onset. Together with group differences in the lateral topography of valence effects, these results are discussed as evidence of deficient automatic processing of emotionally potent stimuli in schizophrenia.
\end{abstract}

Descriptors: Schizophrenia, Emotion, Affect, RSVP, MEG, MNE

Affective symptoms ranging from affective flattening to depression and anxiety are prominent in schizophrenia and are represented in common diagnostic instruments and symptom scales. Psychopathological models, however, often focus on cognitive and neuropsychological deviance. Experimental studies of affective processing in schizophrenia, typically focused on affect recognition or categorization (like emotional face expression), have offered inconsistent evidence, varying from "normal" (e.g., Flack, Cavallaro, Laird, \& Miller, 1997; Kosaka et al., 2002; Wolf et al., 2004) to deficient performance in schizophrenia patients (Horley et al., 2001; Kohler, Bilker, Hagendoorn, Gur, \& Gur, 2000; Kucharska-Pietura \& Klimkowski, 2002; Kucharska-Pietura, David, Dropko, \& Klimkowski, 2002; Silver, Shlomo, Turner, \& Gur, 2002; Streit, Ioannides, et al., 2001; Streit, Wölwer, Brinkmeyer, Ihl, \& Gaebel, 2001; Suslow, Roestle, Ohrmann, \& Arolt, 2003; Ueno et al., 2004) to "normal" reported emotional experience despite poor emotion recognition

The assistance of Drs. Hans Watzl and Karl Pröpster in patient diagnoses, Patricia Andreas and Tzvetan Popov in data acquisition, and Ursula Lommen in data analysis is gratefully acknowledged. The research was supported by the Volkswagen Stiftung, the German Research Foundation (Center Grant FOR 751), and the University of Konstanz (guest professorship for G.A. Miller).

Address reprint requests to: Prof. Dr. Brigitte Rockstroh, Department of Psychology, University of Konstanz, P.O. Box D23, D-78457 Konstanz, Germany. E-mail: Brigitte.Rockstroh@uni-konstanz.de.

Markus Junghöfer is now at the Institute for Biomagnetism and Biosignalanalyses, University of Münster, Germany. performance (Hoeschel \& Irle, 2001; Myin-Germeys, Delespaul, \& deVries, 2000; Silver \& Shlomo, 2002).

A challenge in this literature is disentangling affective and cognitive contributions, as they often co-occur or interact and may not even be distinct (Miller, 1996). For instance, Schneider, Gur, Gur, and Shtasel (1995) found that an impaired ability to discriminate and to experience valence-specific emotions in schizophrenia patients was related to their poorer performance in neuropsychological tests assessing intellectual, attention, abstraction-flexibility, memory, language, spatial, and sensorymotor functions. Similarly, Baudouin, Martin, Tiberghien, Velrut, and Franck (2002; see also Martin, Baudouin, Tiberghien, \& Franck, 2005) reported that performance in an identity task and an emotion classification task were correlated in schizophrenia patients, with poor performance associated with more severe negative symptoms. Along this line, affective symptoms have sometimes been viewed as a consequence of cognitive dysfunction (Johnston, Katsikitis, \& Carr, 2001; Whittaker, Deakin, \& Tomenson, 2001) or a failure to organize cerebral activity at a global level (Taylor, Phan, Britton, \& Liberzon, 2005).

Studies of cortical correlates of affective processing consistently report reduced activation by affective stimuli (including faces) in schizophrenia, with (Schneider et al., 1998; Streit, Ioannides, et al., 2001; Streit, Wölwer, et al., 2001; Ueno et al., 2004) or without (An et al., 2003; Kosaka et al., 2002; Paradiso et al., 2003) poor performance. In response to emotionally salient stimuli, both reduced amygdala activation (Gur et al., 2002; Schneider et al., 1998; Taylor, Liberzon, Decker, \& Koeppe, 
2002) and reduced right ventrostriatal together with bilateral amygdala activation (Taylor et al., 2005) have been found.

Studies examining responses to affective visual stimuli in schizophrenia patients support the hypothesis of abnormal affect processing and modulation. Wolf et al. (2004) presented stimuli from the International Affective Picture System (IAPS; Lang, Bradley, \& Cuthbert, 1998b) to induce facial expressions in schizophrenia patients and found fewer joy/smile (facial EMG) expressions in untreated and olanzapine-treated patients. Gooding, Luh, and Tallent (2001) reported reduced perceptual bias only in response to emotional face chimera, not in response to nonface chimera, and concluded that there is a specific deficit for affective information processing in schizophrenia. Fahim et al. (2004) presented IAPS stimuli during functional magnetic resonance imaging (fMRI) to schizophrenia patients with and without the symptom of flat affect. Patients with flat affect were characterized by a lack of prefrontal activation in contrast to patients with normal affect, who displayed activation in left mesial prefrontal, right orbitofrontal, and left anterior cingulated cortex. Similarly, Takahashi et al. (2004) found reduced activation in prefrontal and subcortical areas in schizophrenia patients relative to healthy controls. Introducing acoustic startle probes during the presentation of IAPS pictures, Schlenker, Cohen, and Hopmann (1995) found smaller startle reflex during affective than neutral slides in patients with apparent deficit in affective expression, unlike the linear modulation of the startle response seen in nonpatients, with largest amplitudes during unpleasant and smallest during pleasant pictures (though this contrasts with findings by Curtis, Lebow, Lake, Katsanis, \& Iacono, 1999, of similar patterns of affective startle modulation in schizophrenia patients, their first-degree relatives, and healthy controls).

Rapid serial visual presentation (RSVP) of IAPS stimuli, a paradigm developed by Junghöfer, Elbert, Tucker, and Rockstroh (2001), is a particularly promising means to probe early, preattentive responses. When stimuli were presented in rapid succession at $3 \mathrm{~Hz}$ (every $333 \mathrm{~ms}$ ) or $5 \mathrm{~Hz}$ (every $200 \mathrm{~ms}$ ), rates too fast for conscious discrimination of specific affective content, magnetoencephalography (MEG)-assessed cortical activity in healthy participants discriminated emotionally arousing from neutral stimuli beginning about $120 \mathrm{~ms}$ after stimulus onset (Junghöfer et al., 2003). Source modeling of EEG data revealed bilateral but right-hemisphere-dominant sources of this early activation in the extended visual cortices (see Schupp, Junghöfer, Weike, \& Hamm, 2003, for CSD and Schupp et al., 2006,for Minimum Norm Estimates). This finding has been crossvalidated by parallel fMRI studies using RSVP (Junghöfer, Schupp, Stark, \& Vaitl, 2005).

In the present study, the affective RSVP design was used to study individuals with schizophrenia with magnetoencephalography-based assessment of regional brain activity. As noted above, the RSVP is a simpler paradigm than that of most studies of affective processing in schizophrenia, with its focus on automatic, preattentive processing. Nevertheless, the rapid stream of stimuli presents a substantial processing load at early stages, and increased processing load has often been useful in revealing cognitive deficits in schizophrenia. Although the affective RSVP paradigm has not been used with schizophrenia patients, evidence of impaired performance under high workload and of early processing deficits has been obtained in diverse nonemotional tasks, including visual hierarchical processing (Johnson, Lowery, Kohler, \& Turetsky, 2005), visual context effects (Silverstein, et al., 1996), auditory gating (Adler et al., 1982; Bramon, Rabe-
Hesketh, Sham, Murray, \& Frangou, 2004; Hanlon et al., 2005), saccade-antisaccade tasks (Curtis, Calkins, \& Iacono, 2001), and visual steady-state responses to contrast-reversing stimuli (Kim, Zemon, Saperstein, Butler, \& Javitt, 2005). Thus, there are good grounds to anticipate effects in patients as early as 100 to $300 \mathrm{~ms}$ after stimulus onset if affective processing abnormalities arise relatively early in the processing stream.

Patients were predicted to show a deficit in automatic, preattentive discrimination of emotionally potent pictures, either confined to pleasant stimuli (reflecting the symptom of anhedonia) or generalized, appearing equally for pleasant and unpleasant stimuli (reflecting the symptom of flat affect). The assessment of regional activation patterns via high-density MEG allowed evaluation of temporally and regionally specific activation patterns that could guide characterization of the affective processing deficit. MEG responses were analyzed in terms of the common distinction between emotional valence and emotional arousal discussed by many authors (e.g., Heller, Nitschke, \& Miller, 1998; Lang, Bradley, \& Cuthbert, 1998a). Following reports from functional brain imaging studies, generally weaker brain activation was expected in individuals with schizophrenia than in a healthy comparison group. In line with EEG and MEG studies of face recognition or picture presentation, delayed and/ or reduced activation was expected for posterior (occipital, parietal) but also anterior (inferior prefrontal) areas (e.g., Streit, Ioannides, et al., 2001). A primarily right-hemisphere abnormality might be expected based on studies of facial emotional expression in schizophrenia (Kucharska-Pietura \& Klimkowski, 2002; Kucharska-Pietura et al., 2002). On the other hand, frequently reported left-hemisphere abnormalities in schizophrenia (e.g., Shenton, Dickey, Frumin, \& McCarley, 2001) have been related primarily to cognitive dysfunction, a sensory gating deficit (Thoma et al., 2003), or symptoms such as auditory hallucinations (e.g., Tiihonen et al., 1992).

\section{Methods \\ Participants}

The schizophrenia sample comprised 12 male inpatients on a university inpatient research unit (mean $\pm S D$ age $28.1 \pm 5.9$ years). Patients were naive to the experimental procedures. Experienced senior psychiatrists with long experience evaluating patients for research on the unit used ICD-10 criteria for diagnoses. Nine patients received an ICD diagnosis of paranoidhallucinatory schizophrenia (20.0), and 3 met criteria for schizoaffective disorder (F25). Neurological conditions (such as closed head injury or epilepsy) were ruled out. All patients were medicated, 9 receiving atypical neuroleptics, 3 typical neuroleptics. For 8 patients, neuroleptics were combined with antidepressives or benzodiazepines. Duration of illness varied between 0.5 and 15 years, with a mean of 4.8 years. Right-handedness was verified for 10 patients by a modified version (in which participants were asked to demonstrate movements) of the Edinburgh Inventory (Oldfield, 1971). Two patients were lefthanded.

The clinical status of each patient was assessed by the psychiatrist in charge on the day of MEG assessment using the Brief Psychiatric Rating Scale (BPRS; Lukoff, Nuechterlein, \& Ventura, 1986) and the Positive and Negative Symptom Scale (PANSS; Kay, Fiszbein, \& Opler, 1987). Mean scores were $43.5 \pm 10.1$ (range 30-59) for the BPRS, $12.9 \pm 5$ (range 7-22) 
for the PANSS-P, $19.4 \pm 5.9$ (range 7-27) for the PANSS-N, and $35.7 \pm 7.8$ (range 21-45) for PANSS-G. Affective symptoms were specifically addressed by (a) the sum of BPRS-subscales depression, affective flattening, and emotional withdrawal (group mean 8.83, range 3-13), and (b) the affective flattening item of the PANSS-N (mean 3.2, range 1-6).

For the control group, 12 right-handed, healthy, male participants (mean $\pm S D$ age $28.0 \pm 2.7$ years) were recruited from a larger pool of healthy participants who volunteer to participate in various studies in the department. Control participants were selected to match patients with respect to age and gender. It was ascertained by interview that no control participant had suffered from any neurological disorder. Although groups were comparable with respect to age and gender, as is often the case in studies of schizophrenia they differed in years of education, on average 16.6 years for the control group, 11.6 years at school for patients, $t(22)=4.49, p=.001$. Participants received a payment of about U.S. $\$ 10$ for participation.

\section{Design and Procedure}

Before the start of an experimental session each participant was fully informed about the purpose and protocol of the study and about guidelines for human rights protection. Written consent was obtained from every participant.

Based on the normative ratings of emotional valence and arousal, as well as analysis of physical picture parameters, 300 IAPS pictures were selected for three categories of 100 pictures each: high-arousal pleasant pictures of erotica, sports, and so forth, low-arousal neutral pictures of road traffic, a supermarket, and comparable scenes, and high-arousal unpleasant pictures of human attack, mutilation, and so forth. The high- and lowarousal picture sets did not differ statistically in brightness, color distribution, contrast, physical complexity (JPEG file size at $90 \%$ quality), or mean spatial frequency.

Pictures were presented in two runs of 200 presentations each. In each run, the series of pictures was shown without perceivable gap for $333 \mathrm{~ms}$ each ( $3 \mathrm{~Hz}$ presentation rate). One run alternated among the 100 pleasant and the 100 neutral pictures, and the other run alternated among the 100 unpleasant and the same 100 neutral pictures in a different sequence. The order of runs was counterbalanced across participants. Randomized and alternating rapid serial presentation of IAPS pictures results in very similar ERP effects (Junghöfer et al., 2001; Schupp et al. 2003), and Schupp et al. (2006) showed that early ERP components do not habituate in the alternating paradigm.

Participants were asked to keep their eyes focused on a small central fixation cross that overlay each picture while viewing them. Participants were instructed to observe the picture series carefully without any additional task. MEG was recorded with the participant lying horizontally (see below), with stimuli presented via a video projection system on a screen mounted on the ceiling of the shielded chamber.

After MEG acquisition, each participant was asked to rate the valence and emotional arousal of 36 representative IAPS pictures, 12 from each affective category. The selected subsets of pleasant and unpleasant pictures were matched on arousal based on the IAPS norms (Center for the Study of Emotion and Attention, 2004; Lang, Bradley, \& Cuthbert, 2004). Pictures were presented without time limits in randomized picture order, and ratings were obtained with a computerized version of the Self Assessment Manikin (SAM; Bradley \& Lang, 1994). Each affective dimension was evaluated on a 9-point scale, with higher numbers indicating evaluation as more pleasant or arousing.

\section{Data Acquisition and Analysis}

MEG was recorded with a 148-channel whole-head neuromagnetometer (MAGNES 2500 WH, 4D Neuroimaging, San Diego, CA) with participants in a horizontal position. A video camera inside the chamber monitored the participant's behavior and compliance throughout the experiment. Standard head-position reference points and head shape were digitized with a Polhemus 3Space Fasttrack prior to MEG recording. The participant's head position relative to the pickup coils of the sensor was measured before and after recording. The MEG signal was recorded continuously with a $678.17-\mathrm{Hz}$ sampling rate. An online bandpass filter was set to $0.1-200 \mathrm{~Hz}$ (Butterworth filter, roll-off $3 \mathrm{db} /$ octave). Vertical and horizontal eye movements were recorded with four electrodes, near the left and right outer canthi and above and below the right pupil. The electrocardiogram was recorded with two electrodes placed on the left and right medial forearms. EOG and EKG recording was performed with a Synamps amplifier and Neuroscan version 3.2 software.

MEG data were EKG- and noise-corrected and band-pass filtered off-line between 1.5 and $50 \mathrm{~Hz}$ using 4D NeuroImaging algorithms. Data editing and artifact rejection were based on the method for statistical control of artifacts developed by Junghöfer, Elbert, Tucker, and Rockstroh (2000): Calculating the absolute maximum amplitude, the maximum temporal gradient, and the standard deviation across the whole time interval for each individual trial and sensor, global or regional artifacts were detected if one of the three parameters in a given trial exceeded a threshold determined by the parameter distribution across all trials within a specific sensor as well as the distribution of the calculated thresholds across all sensors. Regional artifacts were interpolated by spherical splines if the calculated goodness of interpolation (calculation based on spherical test functions and depending on position and distribution of extracted sensors) did not fall below a given threshold, identically defined for all runs and participants. This editing procedure is especially recommended for high-density EEG/MEG measures.

After artifact correction, average event-related magnetic fields were calculated for each picture category, sensor, and participant. The amplitude of event-related responses was defined relative to a baseline that averaged one stimulus epoch of $333 \mathrm{~ms}$ before and one after the present trial. Thus, for emotional stimuli these baseline intervals were the two adjacent neutral trials, and for neutral stimuli they were the two adjacent emotional pictures.

The amplitude and distribution of the measured event-related magnetic fields depend on individual head position within the sensor coordinate system as well as individual head geometry (especially head size). An estimation of the underlying neuronal generators, such as the L2- Minimum-Norm Estimate (L2-MNE; Hämäläinen \& Ilmoniemi, 1984), however, is independent of such individual factors and allows statistical tests across participant groups and affective conditions. The L2-MNE served as an inverse distributed source modeling method to examine the cortical generator of the magnetic field activity without a priori assumptions about the location and/or number of current sources. The present analyses were based on an isotropic spherical head model with 2 (azimuth and polar direction) $\times 197$ dipolar sources evenly distributed on an inner spherical shell. Sphere position and radius were estimated in order to optimally fit the digitized head shape. As a trade-off between noise sensitivity and 
spatial resolution (Hauk, Keil, Elbert, \& Müller, 2002), the source shell depth was set at $35 \%$ of the distance from the scalp to the center of the head on an individual basis. Dipole strength at a given dipole site was obtained as the square root of the sum of squared L2 values for each of the two tangential orientations, for each time point for each data set (categories and participants). The mean global source strength was estimated as the mean dipole strength across all 197 sites for each time point.

For each sample data point and dipole site, a Group (patients vs. controls) $\times$ Valence (unpleasant minus same-run neutral vs. pleasant minus same-run neutral) ANOVA was conducted on the L2-MNE measures, in order to identify spatial regions and latencies of significant group differences and/or Group $\times$ Valence interactions. To avoid false positives, a significance criterion of $p<.01$ was used, and significant effects were considered only when they were observed for at least 10 consecutive sampling points $(15 \mathrm{~ms})$ and two neighboring voxels. Waveforms in Figure 1 indicate that controls tended to have an earlier peak for the component peaking around $100 \mathrm{~ms}$ and also that controls tended to have a more pronounced, slower component approximately $130-250 \mathrm{~ms}$ following picture onset. Scoring windows were selected to avoid confounding group differences in latency or component structure with group differences in amplitude. ${ }^{1} \mathrm{At}$ a short, fixed SOA of $333 \mathrm{~ms}$, activation by emotional material within approximately the first $100 \mathrm{~ms}$ cannot easily be distinguished from activation prompted by the preceding neutral stimulus; thus results before $90 \mathrm{~ms}$ were not analyzed further. Analyses for the 100-160 ms and 160-300 ms epochs are included in Table 3, below, but are discussed only where they provided additional information.

For each epoch, the impact of emotional features of stimuli on the evoked magnetic responses was analyzed by two ANOVAs, with the between-participants factor Group (patients vs. controls) and three within-participants factors: either Arousal or Valence and both Caudality (anterior vs. posterior) and Hemisphere (left vs. right). The arousal analysis compared (a) the average of pleasant and unpleasant responses with (b) the average of the two sets of neutral responses in one ANOVA. The valence analysis compared difference scores (unpleasant minus same-run neutral vs. pleasant minus samerun neutral stimuli) in the other ANOVA. These two analyses thus examined conceptually orthogonal aspects of affective processing. Simple-effects ANOVAs were conducted to explore significant interactions.

Because handedness might affect lateral asymmetry of brain activity, the main analyses were redone excluding the two lefthanded patients. Because results were very similar, only results for the entire sample are reported.

Valence and arousal ratings were not available for 1 patient. For the remaining 11 patients and 12 controls, ratings obtained from an exemplary set of positive, neutral, and negative pictures were submitted to Group (patients vs. controls) $\times$ Emotion (positive vs. neutral vs. negative pictures) ANOVAs separately for valence and arousal ratings. Within-group tests of ratings were done in the absence of interactions with group as an ad-

\footnotetext{
${ }^{1}$ The $90-130$-ms scoring window captured controls' early activity without the later activity, and the $100-160$-ms window was weighted toward representing patients' responses. There was no difference for the two windows in whether a factor reached the .05 significance level (see Table 3, below).
}

Table 1. Means (SD) of Self-Assessment Manikin Ratings for Control and Patient Groups

\begin{tabular}{lcc}
\hline \hline & Pleasure ratings & Arousal ratings \\
\hline $\begin{array}{l}\text { Pleasant } \\
\text { Controls }\end{array}$ & $6.19(0.5)$ & \\
$\quad$ Patients & $6.47(1.2)$ & $5.30(1.2)$ \\
Neutral & & $5.86(1.4)$ \\
$\quad$ Controls & $5.28(0.1)$ & $2.33(1.3)$ \\
$\quad$ Patients & $5.55(0.8)$ & $3.09(0.6)$ \\
Unpleasant & & $7.01(1.5)$ \\
$\quad$ Controls & $2.24(0.3)$ & $6.99(0.9)$ \\
Patients & $2.67(1.4)$ & \\
\hline \hline
\end{tabular}

Note. Higher numbers represent higher arousal or pleasantness (positive valence) on 9-point rating scales.

ditional manipulation check, to assure effective manipulation of affect in each group.

\section{Results}

\section{Affective Ratings}

Table 1 presents mean values for the arousal and valence ratings for control and schizophrenic participants. There was no main effect of or interaction with the group factor, indicating similar evaluation of emotional material in patients and control participants. A main effect of valence, $F(2,42)=155.76, p<.001$, indicated that pleasant pictures were rated higher in valence than neutral pictures, $t(22)=4.82, p<.001$, and unpleasant pictures were rated lower than neutral pictures, $t(22)=16.43, p<.001$. A main effect of arousal, $F(2,42)=161.11, p<.001$, indicated that unpleasant and pleasant pictures were rated as more arousing than neutral pictures, $t \mathrm{~s}(22)>10.8, p s<.001$. Unpleasant pictures were rated as slightly more arousing than pleasant pictures, $t(22)=7.41, p<.001$.

\section{Affective Evoked Brain Activity}

Figure 1 illustrates the time course of global brain activity (minimum norm equivalents, MNE) by group and affect, separately for the four regions. The largest peaks are evident over posterior regions around $100 \mathrm{~ms}$ after stimulus onset, with evident group differences in amplitude and peak latency. An apparently later maximum in the patient group was not significant, however, in an ANOVA performed on latencies of the first maximum.

Tables 2 and 3 present means, standard deviations, and significant effects of arousing versus neutral pictures on evoked brain activity for the three analysis epochs. The Group $\times$ Arousal $\times$ Caudality $\times$ Hemisphere ANOVA investigated whether the groups differed in regional activation evoked by pleasant and unpleasant (combined) versus neutral pictures.

Arousal and caudality main effects and Arousal $\times$ Caudality and Group $\times$ Caudality interactions in each of the three epochs were qualified by a Group $\times$ Arousal $\times$ Caudality interaction in each epoch (see Figure 2 and Table 3). Follow-up tests indicated that high-arousal pleasant and unpleasant pictures consistently prompted larger responses than did neutral pictures in controls, especially caudally (Arousal $\times$ Caudality: 90-130 ms, $F[1,11]=9.37, \quad p<.05 ; 100-160 \mathrm{~ms} F=18.82 ; 160-300 \mathrm{~ms}$ $F=6.47, p \mathrm{~s}<.05)$, but not in patients $\left(F_{\mathrm{s}}<2, p \mathrm{~s}>.2\right.$ in all epochs). Follow-up tests also confirmed simple main effects for Arousal for the posterior areas in controls (90-130 ms: 


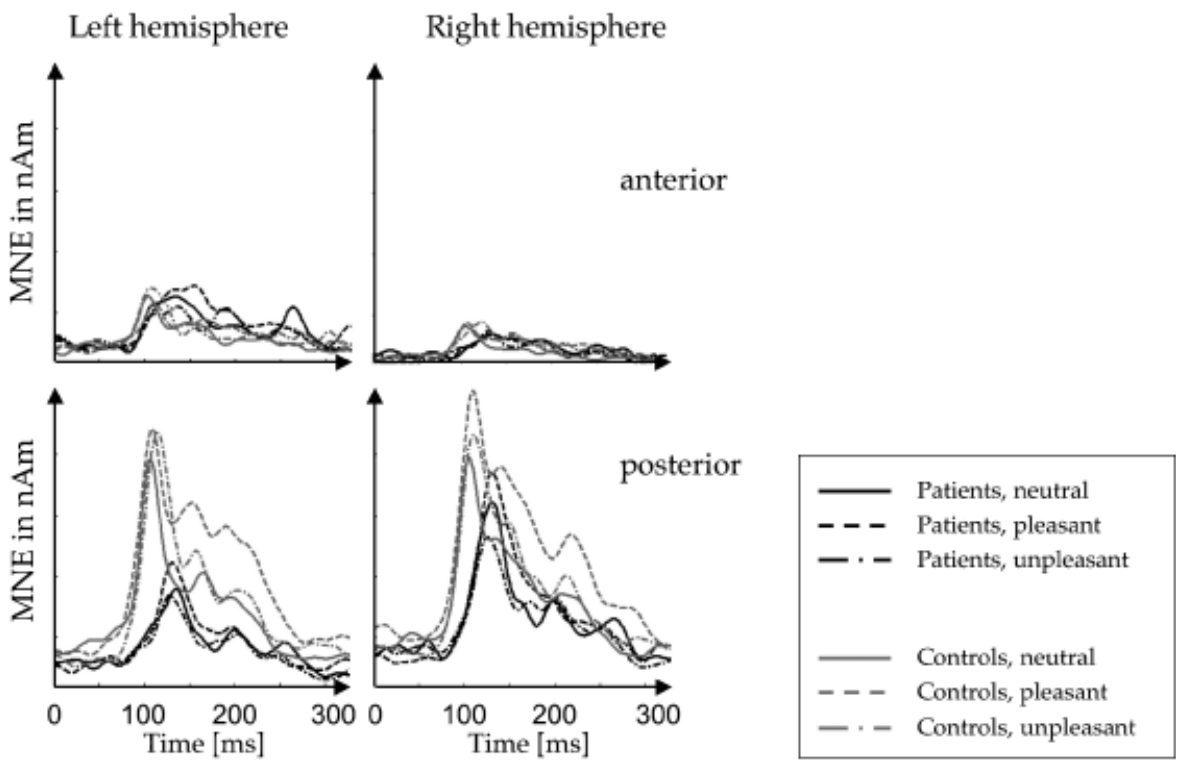

Figure 1. Time course between 0 and $300 \mathrm{~ms}$ after stimulus onset (abscissa) of global activity (L2-MNE in nanoamp-meters, ordinates), averaged separately for left anterior, right anterior, left posterior, and right posterior brain regions.

Table 2. Means (SD) for Minimum Norm Equivalents by Group, Stimulus Arousal Level, Brain Region, and Epoch

\begin{tabular}{|c|c|c|c|c|c|c|}
\hline \multirow[b]{3}{*}{ Region } & \multicolumn{6}{|c|}{ Epoch } \\
\hline & \multicolumn{2}{|c|}{$90-130 \mathrm{~ms}$} & \multicolumn{2}{|c|}{$100-160 \mathrm{~ms}$} & \multicolumn{2}{|c|}{$160-300 \mathrm{~ms}$} \\
\hline & Emotional & Neutral & Emotional & Neutral & Emotional & Neutral \\
\hline \multicolumn{7}{|l|}{ Left frontal } \\
\hline Controls & $0.59(0.2)$ & $0.57(0.2)$ & $0.58(0.2)$ & $0.52(0.1)$ & $0.47(0.1)$ & $0.41(0.1)$ \\
\hline Patients & $0.49(0.2)$ & $0.50(0.2)$ & $0.53(0.2)$ & $0.52(0.2)$ & $0.46(0.2)$ & $0.44(0.1)$ \\
\hline \multicolumn{7}{|c|}{ Right frontal } \\
\hline Controls & $0.72(0.2)$ & $0.70(0.2)$ & $0.68(0.1)$ & $0.66(0.2)$ & $0.55(0.1)$ & $0.51(0.1)$ \\
\hline Patients & $0.70(0.4)$ & $0.65(0.3)$ & $0.76(0.4)$ & $0.68(0.3)$ & $0.62(0.3)$ & $0.60(0.2)$ \\
\hline \multicolumn{7}{|c|}{ Left posterior } \\
\hline Controls & $1.20(0.5)$ & $1.09(0.5)$ & $1.18(0.4)$ & $1.01(0.4)$ & $0.82(0.2)$ & $0.71(0.1)$ \\
\hline Patients & $0.73(0.3)$ & $0.70(0.3)$ & $0.79(0.3)$ & $0.74(0.3)$ & $0.60(0.2)$ & $0.56(0.1)$ \\
\hline \multicolumn{7}{|c|}{ Right posterior } \\
\hline Controls & $1.27(0.5)$ & $1.15(0.4)$ & $1.26(0.4)$ & $1.12(0.4)$ & $0.88(0.3)$ & $0.77(0.2)$ \\
\hline Patients & $0.60(0.6)$ & $0.92(0.5)$ & $1.07(0.6)$ & $0.96(0.4)$ & $0.76(0.2)$ & $0.74(0.2)$ \\
\hline
\end{tabular}

$F[1,11]=6.40, p=.028 ; 100-160 \mathrm{~ms} \quad F=26.07, p=.0003$; 160-300 ms $F=6.15, p=.031$ ), whereas a smaller effect of arousal at anterior areas was confined to later time epochs (90-130 ms $F[1,11]<1 ; 100-160 \mathrm{~ms} F=3.74, p=.079 ; 160-300 \mathrm{~ms}$ $F=4.75, p=.051)$. Patients showed no trend toward anterior differences between arousing and neutral pictures.

The Group $\times$ Valence $\times$ Caudality $\times$ Hemisphere ANOVA investigated whether the groups differed in regional activation evoked by pleasant versus unpleasant pictures (comparing the activation differences between pleasant - neutral and unpleasant - neutral stimulus valence). Whereas groups were equally responsive overall (no group or Group $\times$ Valence effects), Figure 3 illustrates distinct patterns of lateralization of early affective response $^{2}$ in the two groups, Group $\times$ Valence $\times$ Hemisphere for $90-130 \mathrm{~ms} F(1,22)=8.80, p=.007$, and $100-160 \mathrm{~ms} F=9.68$,

${ }^{2}$ Effects not involving group were largely redundant with those in the arousal ANOVA and will not be reported here. Thus, the complete ANOVA table for the valence analysis is not provided. $p=.005$, with the groups showing significant but distinct Valence $\times$ Hemisphere effects. For controls, a Valence $\times$ Hemisphere interaction in the $100-160-\mathrm{ms}$ window, $F(1,11)=10.61$, $p=.007$, indicated that pleasant activation exceeded unpleasant activation in the right hemisphere, $F(1,11)=9.92, p=.009$, but patients did not show this difference (see also Table 4). Controls also showed more left- than right-hemisphere activation for unpleasant pictures in this time window, Hemisphere, $F(1,11)=$ $5.33, p=.04$. On the other hand, for patients, although a Valence $\times$ Hemisphere was obtained in the $90-130-\mathrm{ms}$ window, $F(1,11)=7.78, p=.01$, no simple effects were significant, though the pattern of means did not resemble that found for controls.

\section{Discussion}

Present MEG results for control participants replicated what has been reported using RSVP with nonpatients via EEG (Junghöfer et al., 2001; Schupp et al., 2003) or fMRI (Junghöfer et al., 2006): 
Table 3. Group $\times$ Arousal $\times$ Caudality $\times$ Hemisphere ANOVAs for Minimum Norm Equivalents by Epoch

\begin{tabular}{|c|c|c|c|}
\hline & 90-130 ms epoch & $100-160 \mathrm{~ms}$ epoch & 160-300 ms epoch \\
\hline Group & $F=2.53$, n.s. & $F=1.02$, n.s. & \\
\hline Arousal & $F=4.17, p=.05$ & $F=23.03, p=.0001$ & $F=6.70, p=.02$ \\
\hline Group $\times$ Arousal & & & $F=1.87$, n.s. \\
\hline Caudality & $F=63.67, p=.0001$ & $F=69.38, p=.0001$ & $F=98.60, p=.0001$ \\
\hline Group $\times$ Caudality & $F=8.78, p=.008$ & $F=7.44, p=.01$ & $F=14.14, p=.001$ \\
\hline Arousal $\times$ Caudality & $F=10.20, p=.004$ & $F=17.29, p=.0004$ & $F=5.96, p=.02$ \\
\hline Group $\times$ Arousal $\times$ Caudality & $F=4.25, p=.05$ & $F=6.19, p=.02$ & $F=4.61, p=.04$ \\
\hline Hemisphere & $F=10.14, p=.004$ & $F=16.03, p=.0006$ & $F=29.47, p=.0001$ \\
\hline Group $\times$ Hemisphere & $F=1.30$, n.s. & $F=2.22$, n.s. & $F=3.95, p=.06$ \\
\hline \multicolumn{4}{|l|}{ Arousal $\times$ Hemisphere } \\
\hline Group $\times$ Arousal $\times$ Hemisphere & & $F=2.78$, n.s. & \\
\hline \multicolumn{4}{|l|}{ Caudality $\times$ Hemisphere } \\
\hline Group $\times$ Caudality $\times$ Hemisphere & $F=1.26$, n.s. & & $F=1.25$, n.s. \\
\hline Arousal $\times$ Caudality $\times$ Hemisphere & $F=1.22$, n.s. & & \\
\hline Group $\times$ Arousal $\times$ Caudality $\times$ Hemisphere & $F=1.62$, n.s. & $F=2.98, p=.10$ & $F=1.25$, n.s. \\
\hline
\end{tabular}

Note. Degrees of freedom for each $F$ test are 1 and 22. Empty cells are $F<1$.

Arousing (pleasant and unpleasant) pictures prompted larger posterior brain responses than did neutral pictures even with rapid presentation. This affective distinction was substantially reduced in participants with schizophrenia. Reduced differential responding to affective stimuli has been found in other studies of schizophrenia and has been related to less differential activation in limbic and prefrontal areas and in visual cortex (Gooding et al., 2001; Takahashi et al., 2004). As in previous studies using IAPS stimuli, present results showed an anterior-posterior gradient in responsiveness to affective stimuli. Accordingly, group effects were apparent in posterior activation, with patients failing to show source strength differences when viewing affectively arousing pictures. In contrast, control participants replicated previous data, with greater source strength in posterior regions when viewing emotional than neutral pictures. These results support the hypothesis that the schizophrenia group would show a deficit in automatic, preattentive discrimination of emotionally potent pictures.

An alternative explanation of the reduced activation in patients would be poorer attention, commonly observed in studies

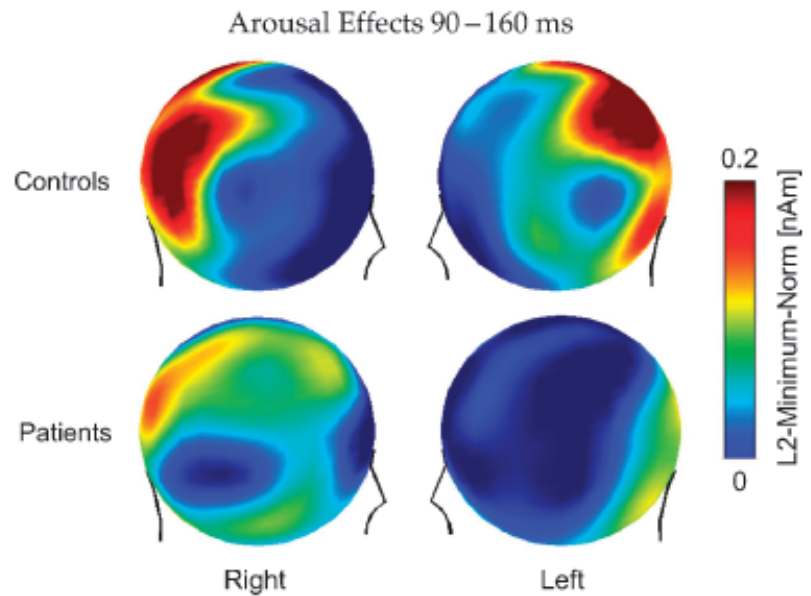

Figure 2. Effect of the arousing nature of stimuli on differences in minimum norm estimates in controls (top) and patients (bottom). Color shadings indicate the differences in MNE between arousing (mean of unpleasant and pleasant pictures) stimuli and their neutral counterparts (mean of neutral stimuli) averaged across the 90-160-ms epoch. Larger differences are represented toward the red end of the spectrum. of schizophrenia and especially in tasks such as the present one with no overt task to foster attention. However, present results showed no main effect of group (in none of the three epochs did the main effect of group reach even a liberal $p<.10$ criterion) or other indication of overall lack of attentiveness or responsiveness. The only reliable effects were interactions sensitive to the brain topography of normal affective responding in this paradigm.

Emotional valence produced differentially lateralized topography in the two groups. Figure 3 suggests just a weaker expression in patients of the pattern found in controls, but closer inspection of the lateralization pattern argues against a complete lack of engagement with affective stimuli. Relative to the rightposterior predominance of the response to pleasant stimuli, unpleasant stimuli increased left-posterior activity in controls. In patients, emotional stimuli mainly affected the right hemisphere, emphasizing a group difference in the left-posterior area. This valence-modulated topography was observed in addition to a right $>$ left asymmetry in both groups. In support of present results, Gonzales-Hernandez, Pita-Alcorta, Cedeno, Dias-Comas, L., and Figueredo-Rodriguez (2003) found an unexpected abnormal lateralization over occipital regions during WCST performance in schizophrenic patients, which they discussed as an indication of a deficit in early information processing. Moreover, Heckers, Goff, and Weiss (2002) described a right $>$ left asymmetry of cerebral blood flow during a passive viewing task. The present study appears to be the first demonstration of such an asymmetry in schizophrenia during affective processing specifically. Reduced left-hemisphere activation in schizophrenia has frequently been reported but has mostly been related to a basic structural (e.g., Shenton et al., 2001) or functional (Thoma et al., 2003; Tiihonen et al., 1992) abnormality. Possibly the smaller left-hemisphere response to affective pictures reflects a broader left-hemisphere dysfunction, whereas highly arousing, unpleasant stimuli are able to activate - at least to some extent - areas involved in emotional processing in the right hemisphere, perhaps even serving a compensatory role. That could account for patients' ratings being normal.

Fast stimulus presentation was used in the present study to prompt preattentive identification of the emotional valence of stimuli, thus, automatic emotional processing. Unpublished work (Saleptsi, 2005) using a similar IAPS design but with 2000 $\mathrm{ms}$ stimulus presentation obtained similar differences between 
Valence Effects $90-160 \mathrm{~ms}$

Patients

Controls

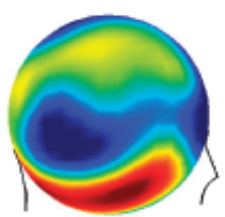

Right

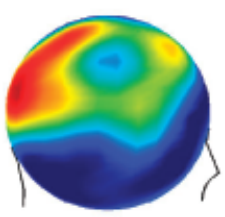

Right

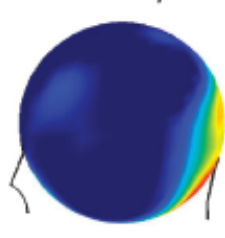

Left

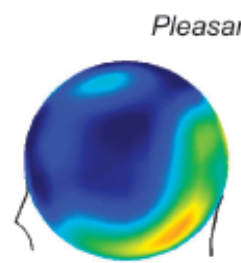

Left
Unpleasant minus Neutral

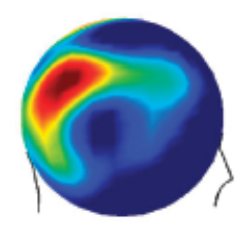

Right

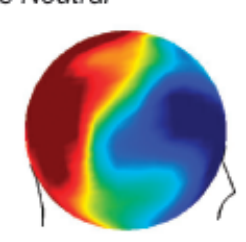

Right

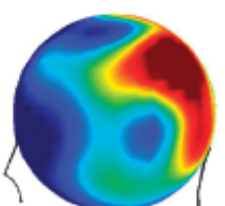

0.2

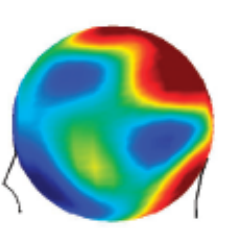

Left

Figure 3. Effect of stimulus valence on differences in minimum norm estimates. Color shadings represent the differences in MNE between unpleasant stimuli and their neutral pairings (top row) or pleasant stimuli and their neutral pairings (bottom row) in patients (left graphs) and controls (right graphs) averaged across the 90-160-ms epoch. Larger differences are represented toward the red end of the spectrum.

schizophrenic and control participants: Ratings of the arousal value of stimuli did not differentiate schizophrenia and control participants, but the former group showed smaller responses in the N1 and P3 component time windows, particularly to pleasant stimuli. Although thorough exploration would require a comparison of fast and slow presentation within the same study, the similarity of results in two studies, with 333 versus $2000 \mathrm{~ms}$ presentation time, argues that present results are not somehow an artifact of rapid presentation. On the contrary, they suggest that differences obtained at longer durations are carried by an abnormality that is evident very early in the processing stream.

The capacity to switch rapidly between stimuli, recognizing the distinct emotional character of each input, may be limited in patients. As a consequence, they cannot cope with processing demands lying well within the range of the natural influx of af- fective information in the human environment. Although apparently no previous study has directly addressed this sensitivity to high processing demands using a fast affective stimulation rate in schizophrenia, commonly reported deficits in attention (e.g., Ito, Kanno, Mori, \& Niwa, 1997), working memory activation at lower processing load (e.g., Jansma, Ramsey, van der Wee, \& Kahu, 1996), and sensory gating (e.g., Hanlon et al., 2005) are compatible with it. For schizophrenia patients, early processing deficits have been inferred from a variety of paradigms noted in the present introduction.

The present samples were limited to men because of availability on the inpatient unit. Given findings of different hemispheric asymmetries in men and women and a modulation of this gender effect in schizophrenia (Rockstroh et al., 2001), a question of generalizability could be raised about present results.

Table 4. Mean Differences (SD) between Unpleasant Minus Same-Run Neutral and Pleasant Minus Same-Run Neutral for Minimum Norm Equivalents by Group, Stimulus Valence Level, Brain Region, and Epoch

\begin{tabular}{|c|c|c|c|c|c|c|}
\hline \multirow[b]{3}{*}{ Region } & \multicolumn{6}{|c|}{ Epoch } \\
\hline & \multicolumn{2}{|c|}{$90-130 \mathrm{~ms}$} & \multicolumn{2}{|c|}{$100-160 \mathrm{~ms}$} & \multicolumn{2}{|c|}{$160-300 \mathrm{~ms}$} \\
\hline & Unpleasant & Pleasant & Unpleasant & Pleasant & Unpleasant & Pleasant \\
\hline \multicolumn{7}{|l|}{ Left frontal } \\
\hline Controls & $0.00(0.1)$ & $0.04(0.1)$ & $0.05(0.1)$ & $0.08(0.1)$ & $0.06(0.1)$ & $0.08(0.1)$ \\
\hline Patients & $-0.04(0.1)$ & $0.01(0.1)$ & $-0.01(0.1)$ & $0.05(0.1)$ & $0.05(0.1)$ & $0.00(0.1)$ \\
\hline \multicolumn{7}{|c|}{ Right frontal } \\
\hline Controls & $0.01(0.2)$ & $0.04(0.2)$ & $-0.02(0.1)$ & $0.05(0.1)$ & $0.03(0.2)$ & $0.05(0.1)$ \\
\hline Patients & $0.08(0.2)$ & $0.01(0.1)$ & $0.10(0.2)$ & $0.07(0.2)$ & $0.00(0.1)$ & $0.05(0.1)$ \\
\hline \multicolumn{7}{|c|}{ Left posterior } \\
\hline Controls & $0.12(0.2)$ & $0.10(0.2)$ & $0.16(0.2)$ & $0.17(0.2)$ & $0.09(0.2)$ & $0.14(0.1)$ \\
\hline Patients & $0.02(0.1)$ & $0.05(0.2)$ & $0.04(0.1)$ & $0.08(0.1)$ & $0.06(0.1)$ & $0.01(0.1)$ \\
\hline \multicolumn{7}{|c|}{ Right posterior } \\
\hline Controls & $0.07(0.2)$ & $0.17(0.2)$ & $0.09(0.1)$ & $0.23(0.1)$ & $0.07(0.2)$ & $0.15(0.2)$ \\
\hline Patients & $0.07(0.2)$ & $-0.01(0.2)$ & $0.11(0.2)$ & $0.10(0.2)$ & $0.01(0.1)$ & $0.04(0.1)$ \\
\hline
\end{tabular}


Some, but not all, psychophysiological work has suggested a bias for men to react more strongly to pleasant pictures and for women to react more strongly to unpleasant pictures, and this relationship may be narrower than broad dimensions of valence and arousal. For example, an fMRI study did not find gender differences in cortical reactivity to pleasant or unpleasant relative to neutral stimuli (Sabatinelli, Flaisch, Bradley, Fitzsimmons, \& Lang, 2004). However, men did show greater extrastriate activity than women specifically during erotic picture perception, possibly reflecting a gender-specific visual mechanism for sexual selection. Although the present sample of high-arousing pleasant stimuli included some erotica, the number of stimuli was not high enough to explicitly distinguish erotic from nonerotic pleasant stimuli in their effects on male controls and male patients.
In sum, present results point to reduced responsiveness to emotionally arousing stimuli and thus an affective processing deficit in individuals with schizophrenia. The character of this deficit spanned both pleasant and unpleasant valence, consistent with the symptom of generally flat affect. However, patients' deviant hemispheric lateralization as a function of valence suggests at least some responsiveness, rather than pervasive affective flatness. Patients' differentiation of valence in the right rather than left hemisphere is consistent with the common report of a compromised left hemisphere in schizophrenia. Markedly reduced responsiveness as early as $100 \mathrm{~ms}$ following stimulus onset, in an early, fundamental, preattentive stage of affective processing, as well as a failure to distinguish unpleasant and pleasant events in left-hemisphere processing, could contribute to a range of cognitive and interpersonal problems in schizophrenia.

\section{REFERENCES}

Adler, L. E., Pachtman, E., Franks, R. D., Pecevich, M., Waldo, M. C., \& Freedman, R. (1982). Neurophysiological evidence for a defect in neuronal mechanisms involved in sensory gating in schizophrenia. Biological Psychiatry, 17, 639-654.

An, S. K., Lee, S. J., Lee, C. H., Cho, H. S., Lee, P. G., Lee, C. I., et al. (2003). Reduced P3 amplitude by negative facial emotional photographs in schizophrenia. Schizophrenia Research, 15, 125-135.

Baudouin, J. Y., Martin, F., Tiberghien, G., Velrut, I., \& Franck, N. (2002). Selective attention to facial emotion and identity in schizophrenia. Neuropsychologia, 40, 503-511.

Bradley, M. M., \& Lang, P. J. (1994). Measuring emotion: The SelfAssessment Manikin and the Semantic Differential. Journal of Behavior Therapy and Experimental Psychiatry, 25, 49-59.

Bramon, E., Rabe-Hesketh, S., Sham, P., Murray, R. M., \& Frangou, S. (2004). Meta-analysis of the P300 and P50 waveforms in schizophrenia. Schizophrenia Research, 70, 315-329.

Center for the Study of Emotion and Attention (2004). The international affective pictures system: Digitized photographis. Gainesville, Fl: The Center for Resaerch in Psychophysiology, University of Florida.

Curtis, C. E., Calkins, M. E., \& Iacono, W. G. (2001). Saccadic disinhibition in schizophrenia patients and their first-degree biological relatives. A parametric study of the effects of increasing inhibitory load. Experimental Brain Research, 137, 228-236.

Curtis, C. E., Lebow, B., Lake, D. S., Katsanis, J., \& Iacono, W. G. (1999). Acoustic startle reflex in schizophrenia patients and their first-degree relatives: Evidence of normal emotional modulation. Psychophysiology, 36, 469-475.

Fahim, C., Stip, E., Mancini-Marie, A., Boualem, M., Malaspina, D., \& Beauregard, M. (2004). Negative socio-emotional resonance in schizophrenia: A functional magnetic resonance imaging study. Medical Hypotheses, 63, 467-475.

Flack, W. F., Cavallaro, L. A., Laird, J. D., \& Miller, D. R. (1997). Accurate encoding and decoding of emotional facial expressions in schizophrenia. Psychiatry, 60, 197-210.

Gonzales-Hernandez, J. A., Pita-Alcorta, C., Cedeno, I., Dias-Comas, L., \& Figueredo-Rodriguez, P. (2003). Abnormal functional asymmetry in occipital areas may prevent frontotemporal regions from achieving functional laterality during the WCST performance in patients with schizophrenia. Schizophrenia Research, 61, 229-233.

Gooding, D. C., Luh, K. E., \& Tallent, K. A. (2001). Evidence of schizophrenia patients' reduced perceptual biases in response to emotion chimera. Schizophrenia Bulletin, 27, 709-716.

Gur, R. E., McGrath, C., Chan, R. M., Schröder, L., Turner, T., Turetsky, B. I., et al. (2002). An fMRI study of facial emotion processing in patients with schizophrenia. American Journal of Psychiatry, 159, 1992-1999.

Hämäläinen, M., \& Ilmoniemi, R. J. (1984). Interpreting measured magnetic fields of the brain: estimates of current distribution. Technical Report TKK-F-A559. Helsinki University of Technology (HUT), Helsinki, Finland.
Hanlon, F. M., Miller, G. A., Thoma, R. J., Irwin, J., Jones, A., Moses, S. N., et al. (2005). Distinct M50 and M100 auditory gating deficits in schizophrenia. Psychophysiology, 42, 417-427.

Hauk, O., Keil, A., Elbert, T., \& Müller, M. M. (2002). Comparison of data transformation procedures to enhance topographical accuracy in time-series analysis of the human EEG. Journal of Neuroscience Methods, 113, 111-122.

Heckers, S., Goff, D., \& Weiss, A. P. (2002). Reversed hemispheric asymmetry during simple visual perception in schizophrenia. Psychiatry Research, 116, 25-32.

Heller, W., Nitschke, J. B., \& Miller, G. A. (1998). Lateralization in emotion and emotional disorders. Current Directions in Psychological Science, 7, 26-32.

Hoeschel, K., \& Irle, E. (2001). Emotional priming of facial affect identification in schizophrenia. Schizophrenia Bulletin, 27, 317-327.

Horley, K., Gonsalvez, C., Williams, L., Lazzaro, I., Bahramali, H., \& Gordon, E. (2001). Event-related potentials to threat-related faces in schizophrenia. International Journal of Neuroscience, 107, $113-120$.

Ito, M., Kanno, M., Mori, Y., \& Niwa, S. (1997). Attention deficits assessed by continuous performance test and span of apprehension test in Japanese schizophrenic patients. Schizophrenia Research, 23, 205-211.

Jansma, J. N., Ramsey, N. F., van der Wee, N. J., \& Kahu, R. S. (2004). Working memory capacity in schizophrenia: A parametric FMRI study. Schizophrenia Research, 68, 159-172.

Johnson, S. C., Lowery, N., Kohler, C., \& Turetsky, B. I. (2005). Globallocal visual processing in schizophrenia: Evidence for an early visual processing deficit. Biological Psychiatry, 58, 937-946.

Johnston, P. J., Katsikitis, M., \& Carr, V. J. (2001). A generalized deficit can account for problems in facial emotion recognition in schizophrenia. Biological Psychology, 58, 203-227.

Junghöfer, M., Bradley, M., Elbert, T., \& Lang, P. (2001). Fleeting images: A new look at early emotion discrimination. Psychophysiology, 38, 175-178.

Junghöfer, M., Elbert, T., Tucker, D. M., \& Rockstroh, B. (2000). Statistical control of artifacts in dense array EEG/MEG studies. Psychophysiology, 37, 175-178.

Junghöfer, M., Sabatinelli, D., Schupp, H. T., Elbert, T. R., Bradley, M. M., \& Lang, P. J. (2006). Fleeting images: Rapid affect discrimination in the visual cortex. NeuroReport, 17, 225-229.

Junghöfer, M., Schauer, M., Neuner, F., Odenwald, M., Rockstroh, B., \& Elbert, T. (2003). Enhanced fear-network in torture survivors activated by RVSP of aversive material can be monitored by magnetic source imaging. Psychophysiology, 40, S51.

Junghöfer, M., Schupp, H., Stark, R., \& Vaitl, D. (2005). Neuroimaging of emotion: Empirical effects of proportional global signal scaling in fMRI data analysis. NeuroImage, 25, 520-526.

Kay, S. R., Fiszbein, A., \& Opler, L. A. (1987). The positive and negative syndrome scale (PANSS) for schizophrenia. Schizophrenia Bulletin, 13, 261-276. 
Kim, D., Zemon, V., Saperstein, A., Butler, P. D., \& Javitt, D. C. (2005). Dysfunction of early-stage visual processing in schizophrenia: Harmonic analysis. Schizophrenia Research, 76, 55-65.

Kohler, C. G., Bilker, W., Hagendoorn, M., Gur, R. E., \& Gur, R. C. (2000). Emotion recognition deficit in schizophrenia: Association with symptomatology and cognition. Biological Psychiatry, 48, 127-136.

Kosaka, H., Omori, M., Murata, T., Iidaka, T., Yamada, H., Okada, T., et al. (2002). Differential amygdala response during facial recognition in patients with schizophrenia: An fMRI study. Schizophrenia Research, 57, 87-95.

Kucharska-Pietura, K., David, A. S., Dropko, P., \& Klimkowski, M. (2002). The perception of emotional chimeric faces in schizophrenia: Further evidence of right hemisphere dysfunction. Neuropsychiatry, Neuropsychology and Behavioral Neurology, 15, 72-78.

Kucharska-Pietura, K., \& Klimkowski, M. (2002). Perception of facial affect in chronic schizophrenia and right brain damage. Acta Neurobiologia Experimentalis, 62, 33-43.

Lang, P. J., Bradley, M. M., \& Cuthbert, B. N. (1998a). Emotion, motivation, and anxiety: Brain mechanisms and psychophysiology. Biological Psychiatry, 44, 1248-1263.

Lang, P. J., Bradley, M. M., \& Cuthbert, B. N. (1998b). Emotion and motivation: Measuring affective perception. Journal of Clinical Neurophysiology, 15, 397-408.

Lang, P. J., Bradley, M. M., \& Cuthbert, B. N. (2004). International affective picture system (IAPS): Instruction manual and affective ratings. Technical Report Aa-6. Gainesville, Fl: The Center for Researh in Psychophysiology, University of Florida.

Lukoff, D., Nuechterlein, K. H., \& Ventura, J. (1986). Manual for the expanded brief psychiatric rating scale. Schizophrenia Bulletin, 12, 594-602.

Martin, F., Baudouin, J. Y., Tiberghien, G., \& Franck, N. (2005). Processing emotional expression and facial identity in schizophrenia. Psychiatry Research, 134, 43-53.

Miller, G. A. (1996). Presidential address: How we think about cognition, emotion, and biology in psychopathology. Psychophysiology, $33,615-628$.

Myin-Germeys, I., Delespaul, P. A., \& deVries, M. W. (2000). Schizophrenia patients are more emotionally active than is assumed based on their behavior. Schizophrenia Bulletin, 26, 847-854.

Oldfield, R. (1971). The assessment and analysis of handedness: The Edinburgh Questionnaire. Neuropsychologia, 9, 97-113.

Paradiso, S., Andreasen, N. C., Crespo-Facorro, B., O’Leary, D. S., Watkins, G. L., Boles Ponto, L. L., et al. (2003). Emotions in unmedicated patients with schizophrenia during evaluation with positron emission tomography. American Journal of Psychiatry, 160, 1775-1783.

Rockstroh, B., Kissler, J., Lommen, U., Mohr, B., Eulitz, C., Wienbruch, C., et al. (2001). Altered hemispheric asymmetry of auditory magnetic fields to tones and syllables in schizophrenia. Biological Psychiatry, 49, 694-703.

Sabatinelli, D., Flaisch, T., Bradley, M. M., Fitzsimmons, J. R., \& Lang, P. J. (2004). Affective picture perception: Gender differences in visual cortex? NeuroReport, 15, 1109-1112.

Saleptsi, E. (2005). MEG correlates during affective stimulus processing in posttraumatic stress disorder. Unpublished doctoral dissertation, University of Konstanz.

Schlenker, R., Cohen, R., \& Hopmann, G. (1995). Affective modulation of the startle reflex in schizophrenic patients. European Archives of Psychiatry and Clinical Neuroscience, 245, 309-318.

Schneider, F., Gur, R. C., Gur, R. E., \& Shtasel, D. L. (1995). Emotional processing in schizophrenia: Neurobehavioral probes in relation to psychopathology. Schizophrenia Research, 17, 67-75.

Schneider, F., Weiss, U., Kessler, C., Salloum, J. B., Posse, S., Grodd, W., et al. (1998). Differential amygdala activation in schizophrenia during sadness. Schizophrenia Research, 34, 133-142.
Schupp, H., Junghöfer, M., Weike, A. I., \& Hamm, A. H. (2003). Attention and emotion: An ERP analysis of facilitated emotional stimulus processing. NeuroReport, 14, 1107-1110.

Schupp, H., Stockburger, J., Codispoti, M., Junghöfer, M., Weike, A. I., \& Hamm, A. H. (2006). Stimulus novelty and emotion perception: The near absence of habituation in the visual cortex. NeuroReport, 17, 365-369.

Shenton, M. E., Dickey, C. C., Frumin, M., \& McCarley, R. W. (2001). A review of MRI findings in schizophrenia. Schizophrenia Research, $49,1-52$.

Silver, H., \& Shlomo, N. (2002). Anhedonia and schizophrenia: How much is in the eye of the beholder? Comprehensive Psychiatry, 43, 65-68.

Silver, H., Shlomo, N., Turner, T., \& Gur, R. C. (2002). Perception of happy and sad facial expressions in chronic schizophrenia: Evidence for two evaluative systems. Schizophrenia Research, 55, 171-177.

Silverstein, S. M., Knight, R. A., Schwarzkopf, S. B., West, L. L., Osborn, L. M., \& Kamin, D. (1996). Stimulus configuration and context effects in perceptual organization in schizophrenia. Journal of Abnormal Psychology, 105, 410-420.

Streit, M., Ioannides, A., Sinnemann, T., Wölwer, W., Dammers, J., Zilles, K., et al. (2001). Disturbed facial affect recognition in patients with schizophrenia associated with hypoactivity in distributed brain regions: A magnetoencephalographic study. American Journal of Psychiatry, 158, 1429-1436.

Streit, M., Wölwer, W., Brinkmeyer, J., Ihl, R., \& Gaebel, W. (2001). EEG correlates of facial affect recognition and categorization of blurred faces in schizophrenic patients and healthy volunteers. Schizophrenia Research, 49, 145-155.

Suslow, T., Roestle, C., Ohrmann, P., \& Arolt, V. (2003). Detection of facial expressions of emotions in schizophrenia. Schizophrenia Research, 64, 137-145.

Takahashi, H., Koeda, M., Oda, K., Matsuda, T., Matsushima, E., Matsuura, M., et al. (2004). An fMRI study of differential neural response to affective pictures in schizophrenia. NeuroImage, 22, $1247-1254$.

Taylor, S. F., Liberzon, I., Decker, L. R., \& Koeppe, R. A. (2002). A functional anatomic study of emotion in schizophrenia. Schizophrenia Research, 58, 159-172.

Taylor, S. F., Phan, K. L., Britton, J. C., \& Liberzon, I. (2005). Neural response to emotional salience in schizophrenia. Neuropsychopharmacology, 30, 984-995.

Thoma, R. J., Hanlon, F. M., Moses, S. N., Edgar, J. C., Huang, M., Weisend, M. P., et al. (2003). Lateralization of auditory sensory gating and neuropsychological dysfunction in schizophrenia. American Journal of Psychiatry, 160, 1595-1605.

Tiihonen, J., Hari, R., Naukkarinen, H., Rimon, R., Jousmaki, V., \& Kajola, M. (1992). Modified activity of the human auditory cortex during auditory hallucinations. American Journal of Psychiatry, 149, 255-257.

Ueno, T., Morita, K., Shoji, Y., Yamamoto, M., Yamamoto, H., \& Maeda, H. (2004). Recognition of facial expression and visual P300 in schizophrenic patients: Differences between paranoid type and nonparanoid patients. Psychiatry and Clinical Neuroscience, 58, 585-592.

Whittaker, J. F., Deakin, J. F., \& Tomenson, B. (2001). Face processing in schizophrenia: Defining the deficit. Psychological Medicine, 31, 499-507.

Wolf, K., Maas, R., Kiefer, F., Eckert, K., Weinhold, N., Wiedemann, K., et al. (2004). The influence of olanzapine on facial expression of emotions in schizophrenia - an improved facial EMG study. German Journal of Psychiatry, 7, 14-19.

(Received September 20, 2005; AcCePted May 4, 2006) 